\title{
VARIAÇÃO ESPAÇO-TEMPORAL (1938-2013) DO USO E OCUPAÇÃO DA TERRA NA REGIÃO DO SACO DA FAZENDA, ITAJAÍ-SC
}

\author{
Fabiane Fisch ${ }^{1}$ \\ Joaquim Olinto Branco ${ }^{2}$ \\ Dagoberto Port ${ }^{3}$ \\ João Thadeu de Menezes ${ }^{4}$
}

Resumo: O objetivo deste trabalho é a análise da variação temporal da cobertura de uso e ocupação do solo de uma região estuarina no litoral centro-norte do Estado de Santa Catarina, reconstruindo as alterações na dinâmica da paisagem em um período de 75 anos (1938 - 2013), além de calcular as variações do Índice de Uso e Ocupação do Solo (IUO) e do Índice de Cobertura Vegetal (ICV). Para a classificação digital de uso e ocupação do solo foi realizada uma classificação visual, em ambiente SIG. Os resultados indicaram que nas décadas de 30, 50 e 70 ocorreram as maiores transformações na área de estudo, sendo que a variação do IUO apontou um crescimento das áreas antropizadas e o ICV demonstrou uma redução das áreas com vegetação. Estudos desta natureza constituem-se ferramentas importantes para a tomada de decisão dos gestores municipais, na busca de um crescimento mais harmônico das cidades, compatibilizando as necessidades dos moradores por moradias e serviços públicos com os remanescentes naturais, que tem igual importância para a qualidade de vida da população.

Palavras-chave: Uso e ocupação da terra. Variação temporal. Estuário. Itajaí

\section{SPATIO-TEMPORAL VARIATION (1938-2013) OF LAND USE AND LAND COVER OF THE SACO DA FAZENDA REGION, ITAJAÍ-SC}

Abstract: The purpose of this work is the analysis of spatio-temporal variation in land use and land cover of an estuary area in north-central coast of the state of Santa Catarina, reconstructing the changes in landscape dynamics in a 75-year period (1938 to 2013), and calculate the variations of the index of land use and land cover (IUO) and vegetation cover index (ICV). For digital classification of cover and land use a visual classification was done in a GIS environment. The results indicated that in the 30's, 50's and 70's occurred the greatest transformations in the study area, being that the variation of IUO pointed a growth of disturbed areas and the ICV showed a reduction in vegetated areas. Studies of this nature are important tools for decision-making of municipal managers in search of a more harmonious growth of cities, aligning the needs of residents for housing and utilities with natural remnants, which have equal importance for the quality of life.

Keywords: Land use and land cover. Temporal variation. Estuary. Itajaí

\footnotetext{
1 Universidade do Vale do Itajaí, Escola do Mar, Ciência e Tecnologia, Itajaí/SC, Brasil, fabianebarragens@hotmail.com, https://orcid.org/0000-0002-9011-7020

2Universidade do Vale do Itajaí, Escola do Mar, Ciência e Tecnologia, Itajaí/SC, Brasil, branco@univali.br, https://orcid.org/0000-0002-3521-1671

3Universidade do Vale do Itajaí, Escola do Mar, Ciência e Tecnologia, Itajaí/SC, Brasil, dagoberto_port@hotmail.com, https://orcid.org/0000-0003-3909-7957

${ }^{4}$ Universidade do Vale do Itajaí, Escola do Mar, Ciência e Tecnologia, Itajaí/SC, Brasil, thadeu@univali.br, https://orcid.org/0000-0003-2829-9975
} 


\section{VARIACIÓN ESPACIO-TEMPORAL (1938-2013) DEL USO Y OCUPACIÓN DE LA TIERRA EN LA REGIÓN DEL SACO DA FAZENDA, ITAJAÍ-SC}

Resumen: El objetivo de este trabajo es el análisis de la variación temporal de la cobertura de uso y ocupación del suelo de una región estuarina en el litoral centronorte del Estado de Santa Catarina, reconstruyendo los cambios en la dinámica del paisaje en un período de 75 años (1938 - 2013 ), además de calcular las variaciones del Índice de Uso y Ocupación del suelo (IUO) y del Índice de Cobertura Vegetal (ICV). Para la clasificación digital de uso y ocupación del suelo se realizó una clasificación visual, en ambiente SIG. Los resultados indicaron que en las décadas de 30, 50 y 70 ocurrieron las mayores transformaciones en el área de estudio, siendo que la variación del IUO apuntó un crecimiento de las áreas antropizadas y el ICV demostró una reducción de las áreas con vegetación. Los estudios de esta naturaleza se constituyen herramientas importantes para la toma de decisiones de los gestores municipales, en la búsqueda de un crecimiento más armónico de las ciudades, compatibilizando las necesidades de los habitantes por viviendas y servicios públicos con los remanentes naturales, que tienen igual importancia para la calidad de vida de la población.

Palabras clave: Uso y ocupación de la tierra.Variación temporal. Estuario. Itajaí

\section{Introdução}

A expansão física de algumas cidades tende a serde forma rápida e desordenada, onde a imprecisão das informações disponíveis acarreta inúmeros transtornos aos órgãos gestores que buscam políticas mais eficazes no gerenciamento do desenvolvimento municipal (MORATO et al., 2011).Detectar as alterações no uso e cobertura do solo compreende a análise de um conjunto de informações temporais disponíveis em imagens de determinados anos, possibilitando que os mapeamentos temáticos sejam mantidos atualizados e auxiliem no gerenciamento dos recursos naturais em áreas com diferentes extensões (LANGLEY et al., 2001; CARVALHO et al., 2002; CARVALHO JR. et al., 2005; LI \& WENG, 2007; BUFFON et al., 2011; FERREIRA et al., 2011).

A escolha de uma escala espaço-temporal tem uma relação direta com os processos ambientais que se pretende analisar, sendo que os diversos componentes ambientais apresentam dinâmicas específicas e estão associados a outros que podem ser naturais (bióticos/físicos) ou antropogênicos em uma permanente inter-relação e coexistência (SANTOS, 2007).

Estas análises espaço-temporais podem estar relacionadas ao ambiente, infraestrutura, características socioeconômicas (ALVES et al., 2009), à cobertura vegetal (PETER et al., 2010; ARAÚJO et al., 2011), à dinâmica da paisagem (PEDRON et al., 2006; PINHEIRO JR et al., 2007; VIEIRA \& BIONDI, 2008; SILVA \& 
SILVA, 2011), ao crescimento e expansão urbana (OLIVEIRA \& COSTA, 2001; SAMPAIO, 2006; UMBELINO \& MACEDO, 2006; BAPTISTA \& CALIJURI, 2007; FERREIRA et al., 2009; MORATO et al., 2011), ao uso e ocupação do solo (ARAÚJO \& FREIRE, 2007; BARROS et al., 2011; ROCHA et al., 2011; CASTRO et al., 2013; PASCOAL JR. et al., 2013), em mapeamentos geotécnicos (XAVIER \& BASTOS, 2010) ou na avaliação da expansão agrícola (FLORES et al., 2012).

Este estudo tem o objetivo analisar de forma espaço-temporal a região do Saco da Fazenda, reconstituindo as alterações na dinâmica da paisagem em um período de 75 anos (1938 - 2013), além de calcular as variações do Índice de Uso e Ocupação do solo (IUO) e do Índice de Cobertura Vegetal (ICV).

\section{Material e métodos}

A área de estudo está localizada na zona urbana da cidade de Itajaí/SC e compreende uma área de 309,45ha (Figura 1). Para a sua delimitação utilizamos o mosaico de fotografias pretérito mais antigo disponível, do ano de 1938. Sobre esse delimitamos uma área (buffer) de $500 \mathrm{~m}$ ao redor da área inundada (Saco da Fazenda), tendo como limite a leste, o guia corrente na margem direita do rio ItajaíAçu (Figura 1). O limite de $500 \mathrm{~m}$ é decorrente da impossibilidade do estabelecimento de um raio maior quando aplicado sobre os outros mosaicos, além de ser uma área considerável para demonstrar as alterações que ocorreram no entorno do Saco da Fazenda durante os 75 anos avaliados (FISCH, 2015; FISCH et al., 2016). Utilizamos fotografias aéreas dos anos de 1938 (bandas: 33/473/1; 33/476/1; 33/477/1), 1957 (banda: 2703/1), 1978 (banda: 1757/1), 1995 (banda: 23/01/01; 25/02/01) e 2004 (bandas: 30, 32, 33, 35, 38), na forma de mosaicos georreferenciados, e imagens de satélite georreferenciadas para os anos de 2009 (imagem do Google Earth de 8/2/2009) e 2013 (imagem do Google Earth de 3/9/2013) (FISCH, 2015; FISCH et al., 2016).

O Saco da Fazenda é uma unidade de conservação municipal (Decreto Municipal no 8.513/2008), gerida pela Fundação Municipal de Meio Ambiente de Itajaí - SC (ITAJAÍ, 2008). A área é denominada pela Lei Municipal o 4.063/04, como baía Afonso Wippel (Figura 1) (ITAJAí, 2004). Sua morfologia é consequência de obras de retificação e fixação do canal de acesso ao Porto de Itajaí (VARGAS, 1935) e está inserida no sistema estuarino da foz do rio Itajaí-Açu, recebendo aporte 
do Ribeirão Schneider e efluentes domésticos do bairro Fazenda (BRANCO, 2000; SCHETTINI, 2008).

Figura 1. Localização geográfica do Saco da Fazenda e área de estudo (imagem Google Earth, 2013).
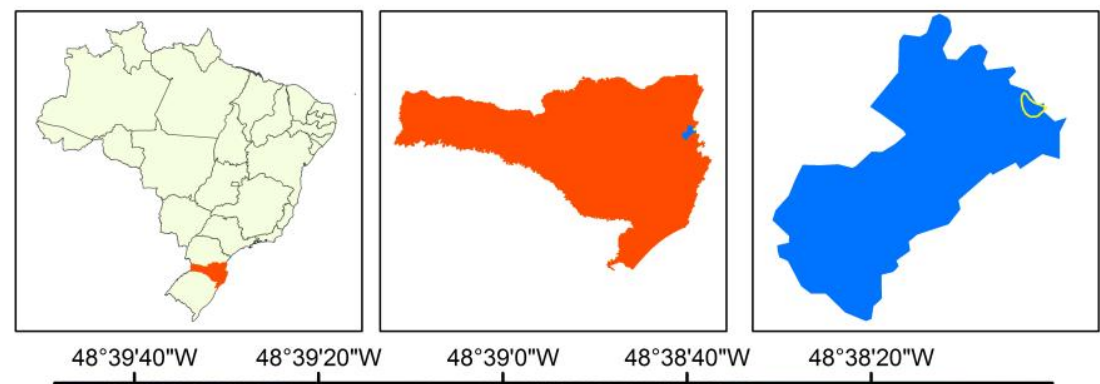

$48^{\circ} 38^{\prime} 20^{\prime \prime} \mathrm{W}$

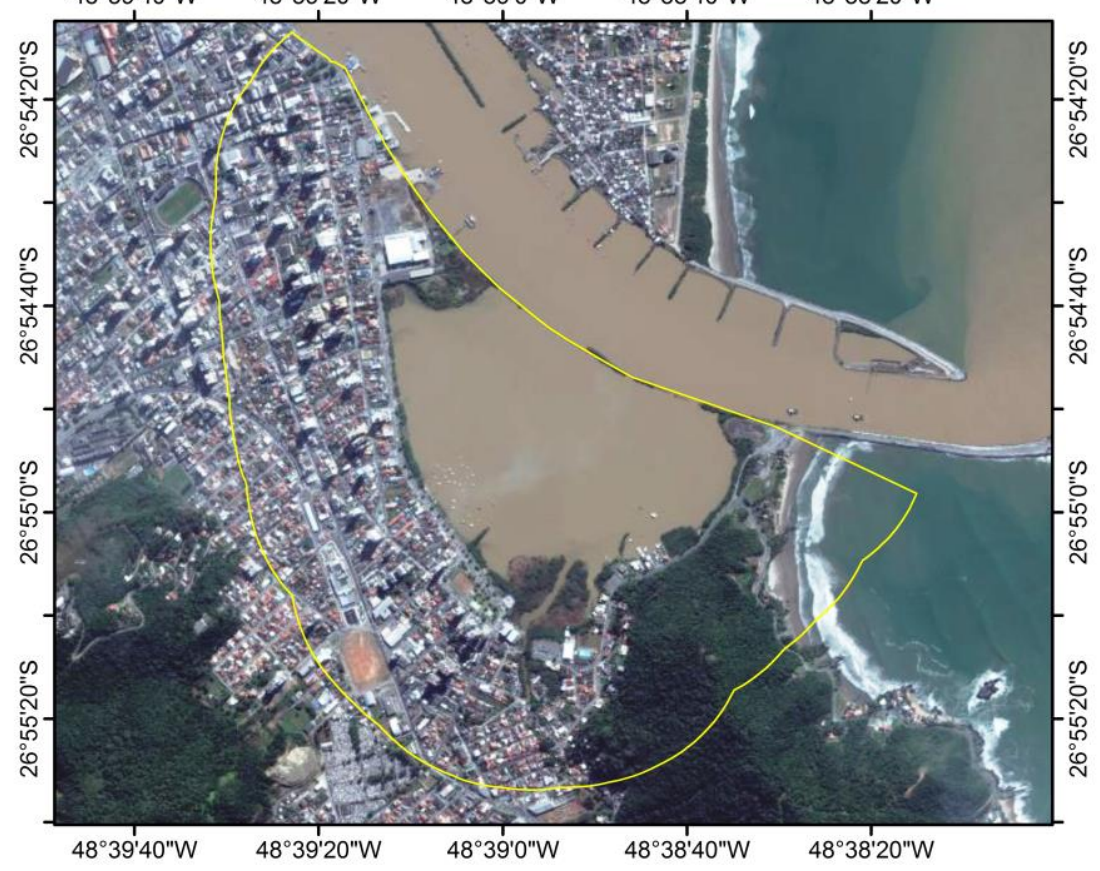

Legenda
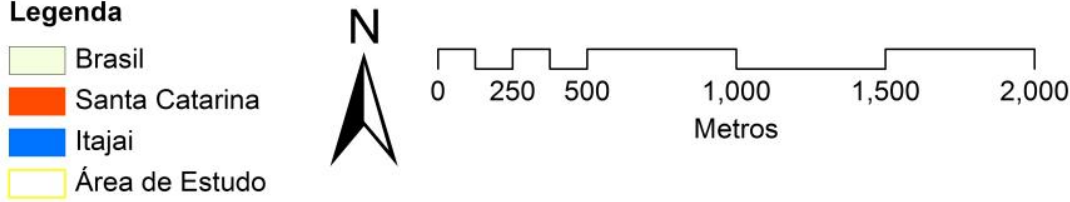

Fonte: FISCH et al., 2016.

\section{Processamento das imagens/fotografias}

A análise espacial foi realizada através do cálculo da área dos polígonos estabelecidos por classificação visual, utilizando o software ArcGis, versão 10.0 (ESRI Inc.). Para a chave de interpretação utilizamos 10 classes que foram selecionadas a partir da análise do conjunto de mosaicos e imagens (Tabela 1) (FISCH, 2015; FISCH et al., 2016). 
Tabela 1. Chave de interpretação das classes utilizadas.

\begin{tabular}{|l|l|}
\hline \multicolumn{1}{|c|}{ Classe } & \multicolumn{1}{c|}{ Descrição } \\
\hline Vegetação herbácea & $\begin{array}{l}\text { Natural ou antropizada (vegetação rasteira disposta de forma } \\
\text { isolada ou em grupo). }\end{array}$ \\
\hline Vegetação arbóreo/arbustiva & $\begin{array}{l}\text { Vegetação com porte arbóreo/arbustivo nas diferentes fases } \\
\text { de sucessão (ciliar ou não). }\end{array}$ \\
\hline Corpos hídricos & Conjunto de arroios, canais e córregos. \\
\hline Planície de inundação & $\begin{array}{l}\text { Área alagável, sujeita ao regime das marés, e com presença } \\
\text { de vegetação halófita lenhosa ou não, resistente a diferentes } \\
\text { teores de salinidade. }\end{array}$ \\
\hline Oceano & Corpo contínuo de água pertencente ao Oceano Atlântico. \\
\hline Areia de praia & Superfícies arenosas existentes. \\
\hline Área urbanizada & $\begin{array}{l}\text { Todas as edificações existentes dentro da área de estudo, } \\
\text { exceto as vias públicas. }\end{array}$ \\
\hline Solo exposto & $\begin{array}{l}\text { Área desprovida de vegetação e que não configura a classe } \\
\text { areia de praia. Decorrente de algum tipo de ação antrópica. }\end{array}$ \\
\hline Ruas & Todas as vias públicas. \\
\hline Encosta rochosa & Afloramento rochoso limítrofe da classe oceano. \\
\hline
\end{tabular}

Posteriormente, foram calculados o Índice de Uso e Ocupação do Solo (IUO) e o Índice de Cobertura Vegetal (ICV). Os índices foram calculados para quantificar a percentagem (variação) da área que foi ocupada ao longo do período avaliado. Os resultados obtidos foram comparados através de correlação linear simples (Pearson).

\section{Índice de Uso e Ocupação do solo (IUO)}

O IUO para cada classe de uso e ocupação do solo e período avaliado foi calculado com a seguinte equação:

$$
\mathrm{IUO}_{\mathrm{i}}=\frac{\left(\mathrm{RU}_{\mathrm{i}}+\mathrm{AU}_{\mathrm{i}}+\mathrm{SE}_{\mathrm{i}}\right)}{\mathrm{AT}} \times 100
$$

Onde: $\mathrm{RU}_{\mathrm{i}}=$ ruas (ha) no ano (i); $\mathrm{AU}_{\mathrm{i}}=$ área urbanizada (ha) no ano (i); $\mathrm{ASE}_{\mathrm{i}}=$ solo exposto (ha) no ano (i)e AT = área de estudo (ha). 


\section{Índice de Cobertura Vegetal (ICV)}

O ICV para cada período avaliado foi calculado com a seguinte equação:

$$
\mathrm{ICV}_{\mathrm{i}}=\frac{\left(\mathrm{VAA}_{\mathrm{i}}+\mathrm{VH}_{\mathrm{i}}+\mathrm{PI}_{\mathrm{i}}\right)}{\mathrm{AT}} \times 100
$$

Onde: $V_{A A}=$ vegetação arbóreo/arbustiva (ha) no ano (i); $\mathrm{VH}_{\mathrm{i}}=$ vegetação herbácea (ha) no ano (i); $\mathrm{PI}_{\mathrm{i}}=$ planície de inundação (ha) no ano (i)e AT = área de estudo (ha).

\section{Resultados e discussão}

A análise espaço-temporal do uso e ocupação do solo para a região do Saco da Fazenda demonstrou que entre as décadas de 30,50 e 70 ocorreram as maiores transformações naregião de estudo, com ênfase no crescimento da área urbanizada e da abertura de novas ruas, sendo necessária para isso a supressão da vegetação herbácea. A partir da classificação das imagens quantificamos a área de cada classe e identificamos as de maior dinâmica evolutiva e as classes invariantes (Tabela 2).

Tabela 2. Evolução espaço-temporal da área de cobertura (ha) das classes analisadas para a região do Saco da Fazenda (AU= Área urbanizada; $\mathrm{SE}=$ Solo exposto; $\mathrm{AR}=$ Areia de praia; $\mathrm{CH}=\mathrm{Corpos}$ hídricos; $\mathrm{VH}=$ Vegetação herbácea; $\mathrm{PI}=$ Planície de inundação; $\mathrm{OC}=$ Oceano; $\mathrm{VAA}=$ Vegetação arbóreo/arbustiva; $\mathrm{ER}=$ Encosta rochosa; $\mathrm{RU}=\mathrm{Ruas})(\mathrm{FISCH}, 2015 ; \mathrm{FISCH}$ et al., 2016).

\begin{tabular}{|c|c|c|c|c|c|c|c|}
\hline \multirow{2}{*}{ Classe } & \multicolumn{7}{|c|}{ Ano } \\
\cline { 2 - 9 } & $\mathbf{1 9 3 8}$ & $\mathbf{1 9 5 7}$ & $\mathbf{1 9 7 8}$ & $\mathbf{1 9 9 5}$ & $\mathbf{2 0 0 4}$ & $\mathbf{2 0 0 9}$ & $\mathbf{2 0 1 3}$ \\
\hline AU & 34,06 & 70,41 & 98,19 & 121,20 & 123,02 & 130,37 & 130,71 \\
\hline SE & 0,67 & 6,18 & 9,70 & 1,55 & 4,62 & 0,13 & 0,18 \\
\hline AR & 3,29 & 4,01 & 6,71 & 2,90 & 3,12 & 3,63 & 3,63 \\
\hline CH & 109,95 & 106,71 & 86,83 & 79,93 & 74,81 & 74,46 & 74,91 \\
\hline VH & 79,38 & 49,21 & 22,44 & 15,01 & 8,28 & 2,53 & 0,77 \\
\hline PI & 10,43 & 2,16 & 2,54 & 8,21 & 6,27 & 0,30 & 1,07 \\
\hline OC & 18,12 & 17,16 & 17,16 & 13,08 & 15,81 & 14,31 & 14,31 \\
\hline VAA & 41,54 & 35,47 & 39,47 & 38,69 & 43,44 & 50,70 & 49,77 \\
\hline ER & 0,41 & 0,23 & 0,16 & 0,15 & 0,17 & 0,18 & 0,18 \\
\hline RU & 11,60 & 17,93 & 26,26 & 28,73 & 29,91 & 32,84 & 33,92 \\
\hline
\end{tabular}

Comparando as imagens classificadas, duas a duas, identificamos as principais alterações ocorridas na cobertura de uso e ocupação do solo para o período analisado. 
Da imagem de 1938 para 1957 verificamos que áreas de vegetação arbóreo/arbustiva e vegetação herbácea são substituídas por área urbanizada. $\mathrm{Na}$ porção sudeste da área de estudo ocorrem alterações no leito do Ribeirão Schneider, com uma grande redução da área de planície de inundação (de 10,43ha para 2,16ha) e desenvolvimento de vegetação herbácea. Na mesma região ocorre também a supressão de uma extensa área de vegetação arbóreo/arbustiva $(4,16 \mathrm{ha})$ que é substituída por vegetação herbácea e solo exposto (Figura 2a e 2b, Tabela 2).

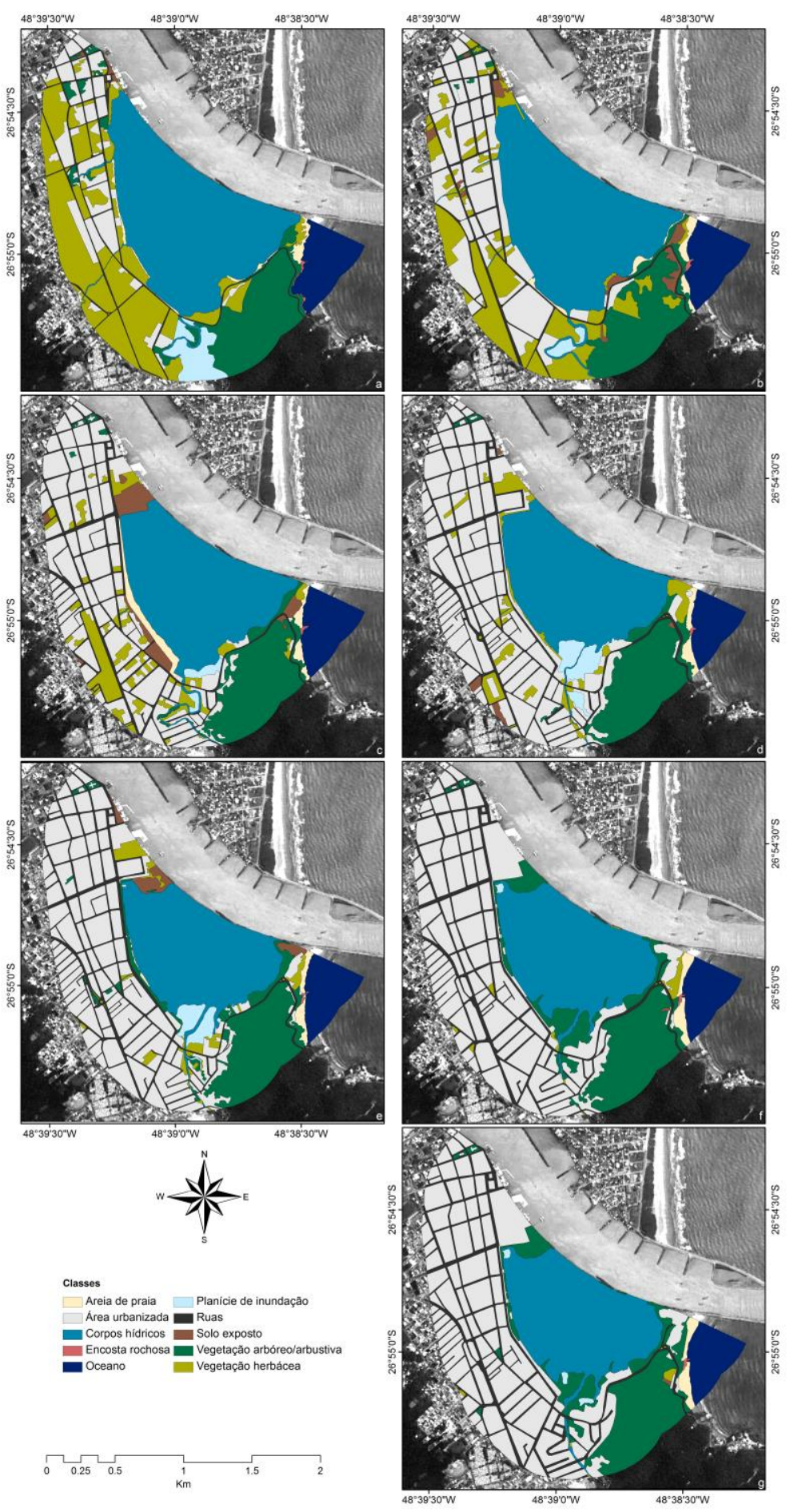


Figura 2. Classes de cobertura de uso e ocupação do solo obtidas após a classificação visual das imagens ( $a=1938 ; b=1957 ; c=1978 ; d=1995 ; \mathrm{e}=2004 ; \mathrm{f}=2009 ; \mathrm{g}=2013)$, sobrepostas a imagem Google Earth (2013).

No período entre 1957 e 1978 diminuem as áreas de vegetação arbóreo/arbustiva e vegetação herbácea que são substituídas por área urbanizada ou solo exposto. Na região sudeste da área de estudo ocorreram novas drenagens da planície de inundação do Ribeirão Schneider, permanecendo a vegetação. Junto à desembocadura deste mesmo curso d'água ocorre o aparecimento de uma nova planície de inundação. Ainda nesta mesma região regenera-se uma área de vegetação arbóreo/arbustiva (3,14ha) antes ocupada por vegetação herbácea e solo exposto. Na porção norte, a área de solo exposto é ocupada por área urbanizada e a de vegetação herbácea é suprimida, ficandoo solo exposto $(4,61 \mathrm{ha})$. Finalmente, na região oeste da área de estudo, observa-se o início das obras de pavimentação da avenida às margens do Saco da Fazenda e o aparecimento de uma grande extensão de areia de praia (Figura 2b e 2c, Tabela 2).

No intervalo entre 1978 e 1995, áreas de vegetação arbóreo/arbustiva, vegetação herbácea e solo exposto são ocupadas por área urbanizada. Na região sudeste da área de estudo ocorre nova retificação do Ribeirão Schneider,com expansão da planície de inundação na desembocadura do ribeirão e supressão de vegetação arbóreo/arbustivaque passa a ser ocupada por área urbanizada. Por sua vez, na região oeste da área de estudo, são finalizadas as obras de pavimentação da avenida as margens do Saco da Fazenda e o surge o desenvolvimento de vegetação na área que era de areia de praia (Figura 2c e 2d, Tabela 2).

No decênio entre 1995 e 2004, continua a ocupação das áreas de vegetação herbácea $(<6,73 \mathrm{ha})$ por área urbanizada $(>1,82 \mathrm{ha})$ e o surgimento de novas áreas de solo exposto (>3,07 ha). A vegetação herbácea de algumas áreas atinge o porte arbóreo. Na região sudeste da área de estudo são feitas novas obras de drenagem da planície de inundação do Ribeirão Schneider. Nesta mesma região, bem como na porção norte da área de estudo, é depositado o bota-fora proveniente da dragagem do estuário entre os anos de 2000 - 2003 (ARAÚJO et al., 2009). Ocorreu ainda, no ano de 2000, o replantio de algumas árvores de mangue (TOGNELLA-DE-ROSA et al., 2002) (Figura 2d e 2e, Tabela 2).

No período entre 2004 a 2009 continua a substituição de áreas de vegetação arbóreo/arbustiva e vegetação herbácea por área urbanizada. Neste intervalo, novas áreas de vegetação herbácea atingem o porte arbóreo. Junto à região sudeste da 
área de estudo é criado o Parque Natural Municipal do Atalaia (PNMA) (Decreto no 8.107/07), abrangendo uma parcela da área de vegetação arbóreo/arbustiva (19,508ha) (ITAJAí, 2007). Neste parque também existe uma área de solo exposto, que pode ter sido originada por algum deslizamento da encosta, ou por ação antrópica. Ainda nesta região, a vegetação da planície de inundação (mangue) do Ribeirão Schneider atinge o porte arbóreo/arbustivo e a área de solo exposto do bota-fora foi ocupada por área urbanizada e vegetação arbóreo/arbustiva. Na região norte, da área de estudo, na área de solo exposto do bota-fora desenvolveu-se vegetação de porte arbóreo/arbustivo (Figura 2e e 2f, Tabela 2).

Finalmente, nos últimos cinco anos (2009-2013), a área urbanizada apresenta uma tendência à estabilização e as áreas de vegetação herbácea estão restritas às praças, canteiros de ruas/avenidas e a alguns fragmentos pontuais. $\mathrm{Na}$ região sudeste da área permanece a área de solo exposto. Em toda a área de estudo, algumas áreas de vegetação arbóreo/arbustiva são suprimidas e a vegetação junto da classe Oceano atinge o porte arbóreo/arbustivo (Figura $2 f$ e 2g, Tabela 2).

A classe correspondente às vias públicas (ruas) aumenta ao longo de todo o período analisado (Figura 2, Tabela 2);

A variação em hectares entre as classes ao longo dos anos pode ser observada na Figura 3 e Tabela 2. As classes areia de praia, planície de inundação e solo exposto apresentaram oscilações em períodos específicos decorrentes de aterros, assoreamentos ou da supressão de vegetação. A vegetação arbóreo/arbustiva obteve um decréscimo entre os anos intermediários e uma elevação dos seus valores para o ano de 2013, decorrentes do processo de sucessão vegetal. Os corpos hídricos foram reduzidos pela retificação dos cursos de água, assoreamento das margens do Saco da Fazenda e canalização de outros recursos hídricos. A classe ruas tem sua variação diretamente relacionada com o aumento das áreas urbanizadas. Estas variações das áreas (hectares), ao longo dos anos, de algumas das classes quando comparadas entre si, apresentam uma forte correlação (Tabela 3). 


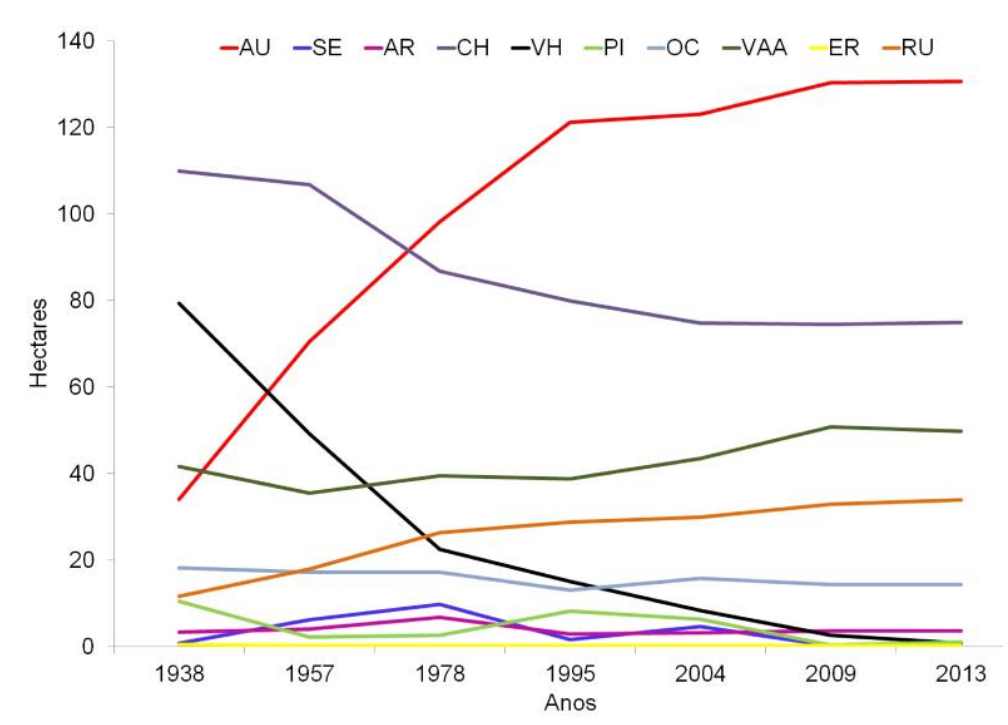

Figura 3. Variação em hectares, entre as classes, ao longo do período analisado (AU: área urbanizada; SE: solo exposto; AR: areia de praia; $\mathrm{CH}$ : corpos hídricos; $\mathrm{VH}$ : vegetação herbácea; PI: planície de inundação; VAA: vegetação arbóreo/arbustiva; ER: encosta rochosa; RU: ruas) (FISCH, 2015; FISCH et al., 2016).

Tabela 3. Matriz de correlação de Pearson entre as diferentes classes (AU: área urbanizada; SE: solo exposto; AR: areia de praia; $\mathrm{CH}$ : corpos hídricos; VH: vegetação herbácea; PI: planície de inundação; VAA: vegetação arbóreo/arbustiva; ER: encosta rochosa; RU: ruas). Os valores do "r" em negrito são significativos $(p<0,05)$.

\begin{tabular}{c|c|c|c|c|c|c|c|c|c|c}
\hline & AU & SE & AR & CH & VH & PI & OC & VAA & ER & RU \\
\hline AU & 1,0000 & & & & & & & & & \\
\hline SE & $-0,1513$ & 1,0000 & & & & & & & & \\
\hline AR & $-0,0835$ & $\mathbf{0 , 7 8 4 2}$ & 1,0000 & & & & & & & \\
\hline CH & $-\mathbf{0 , 9 6 9 6}$ & 0,2041 & 0,0916 & 1,0000 & & & & & & \\
\hline VH & $-\mathbf{0 , 9 9 4 0}$ & 0,0826 & $-0,0092$ & $\mathbf{0 , 9 6 5 6}$ & 1,0000 & & & & & \\
\hline PI & $-0,5040$ & $-0,1755$ & $-0,4114$ & 0,3808 & 0,5658 & 1,0000 & & & & \\
\hline OC & $-\mathbf{0 , 8 3 7 3}$ & 0,5033 & 0,4197 & $\mathbf{0 , 7 8 8 1}$ & $\mathbf{0 , 7 8 0 1}$ & 0,2105 & 1,0000 & & & \\
\hline VAA & 0,5493 & $-0,6210$ & $-0,2217$ & $-0,6379$ & $-0,5597$ & $-0,4141$ & $-0,4463$ & 1,0000 & & \\
\hline ER & $-\mathbf{0 , 8 8 3 9}$ & $-0,2727$ & $-0,2161$ & $\mathbf{0 , 7 9 0 4}$ & $\mathbf{0 , 8 9 4 4}$ & 0,5515 & 0,6630 & $-0,1465$ & 1,0000 & \\
\hline RU & $\mathbf{0 , 9 8 9 6}$ & $-0,1644$ & $-0,0179$ & $\mathbf{- 0 , 9 7 4 9}$ & $\mathbf{- 0 , 9 9 4 1}$ & $-0,5527$ & $\mathbf{- 0 , 7 9 9 8}$ & 0,6302 & $\mathbf{- 0 , 8 4 9 3}$ & 1,0000 \\
\hline
\end{tabular}

No período analisado ocorreram algumas alterações significativas entre as principais classes. Em 1938 a área urbanizada ocupava 11\%, a vegetação herbácea $25,64 \%$, a vegetação arbóreo/arbustiva $13,42 \%$ e as ruas 3,74\% da área de estudo. Atualmente (2013) e com o desenvolvimento da região, principalmente entre os anos de 1957-2009, a área urbanizada passou a ocupar 42,23\%, a vegetação herbácea 0,24\%, a vegetação arbóreo/arbustiva $16,08 \%$ e as ruas $10,96 \%$ da área de estudo.

Estes resultados são similares a outros que identificaram o aumento das áreas antropizadas em detrimento de áreas naturais (ARAÚJO et al., 2008; ALMEIDA et al., 2009; SILVA et al., 2009; HUZUI et al., 2011; VILA NOVA \& TORRES, 2012; PASCOAL JR. et al., 2013). 
Os resultados do Índice de Uso e Ocupação do Solo (IUO) e do Índice de Cobertura Vegetal ICV (Tabela 4) demonstram a existência de uma relação inversa entre estes índices (Figura 4), com uma forte correlação negativa entre os mesmos $\left(r=0,9841 ; R^{2}=0,9684 ; p<0,05\right)$.

Tabela 4. Valores do Índice de Uso e Ocupação (IUO) e do Índice de Cobertura Vegetal (ICV).

\begin{tabular}{c|c|c|c|c|c|c|c}
\hline Ano/Índice & $\mathbf{1 9 3 8}$ & $\mathbf{1 9 5 7}$ & $\mathbf{1 9 7 8}$ & $\mathbf{1 9 9 5}$ & $\mathbf{2 0 0 4}$ & $\mathbf{2 0 0 9}$ & $\mathbf{2 0 1 3}$ \\
\hline IUO & 14,97 & 30,54 & 43,35 & 48,95 & 50,91 & 52,78 & 53,26 \\
\hline ICV & 42,45 & 28,06 & 20,83 & 20,01 & 18,74 & 17,30 & 16,68 \\
\hline
\end{tabular}

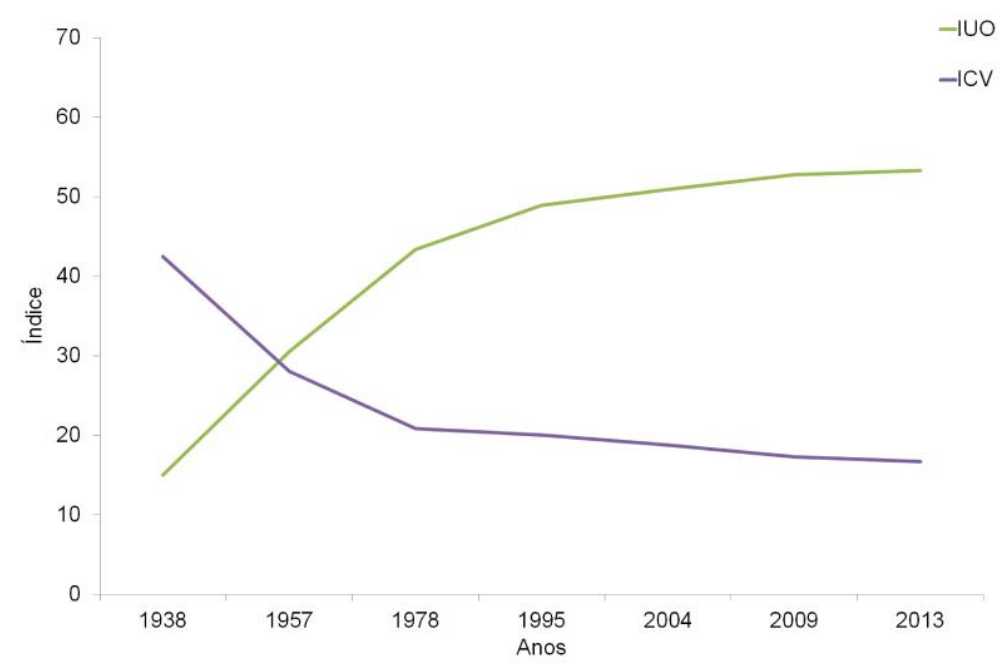

Figura 4. Variação dos valores do Índice de Uso e Ocupação (IUO) e do Índice de Cobertura Vegetal (ICV).

Analisando os resultados obtidos verificamos que em 1938 o Índice de Cobertura Vegetal (ICV) representava 42,45\% da área de estudo e em 2013 apenas 16,68\%. O inverso ocorreu com o Índice de Uso e Ocupação do Solo (IUO) que em 1938 correspondia a 14,97\% da área e no ano de 2013 a 53,26\%. Estes resultados evidenciam o recuo da vegetação ocasionado pelos diferentes processos de urbanização que se intensificaram no decorrer dos 75 anos analisados.

\section{Considerações Finais}

A análise espaço-temporal da paisagem e das alterações ocasionadas pelo uso e ocupação urbana, através de ferramentas como o SIG e do sensoriamento remoto, possibilita a obtenção de dados estatísticos que auxiliam os atores envolvidos em processos decisórios. A análise cumulativa e sinérgica das alterações decorrentes das intervenções ocorridas na área durante o período de 75 anos 
avaliados possibilita uma nova perspectiva para a elaboração/ajuste de ações do Poder Público, bem como na identificação de áreas prioritárias para a conservação.

Os resultados obtidos por este trabalho, especificamente, dimensionam as classes de cobertura de uso e ocupação do solo na região do Saco da Fazenda, num intervalo de tempo de 75 anos. Neste período destaca-se o aumento constante da área das classes de origem antrópica (área urbanizada, solo exposto e ruas) e uma alteração, inversamente proporcional, das classes que compõe o índice de cobertura vegetal (vegetação herbácea, vegetação arbóreo/arbustiva e planície de inundação) e os corpos hídricos. Esta situação encontrada aponta para uma degradação da qualidade ambiental da área de estudo, com o incremento ao longo do tempo de áreas artificiais em detrimento das áreas naturais. O crescimento urbano acarretou na alteração das características naturais do ambiente, a impermeabilização/contaminação do solo, um incremento no número de pessoas e consequente aumento na geração de lixo/esgoto. Estas "alterações" quando consideradas, mesmo que não avaliadas neste trabalho, potencializam a degradação e perda da qualidade do ambiente quando não administradas. $O$ cálculo do Índice de Uso e Ocupação do Solo (IUO) e do Índice de Cobertura Vegetal (ICV), bem como suas variações ao longo dos anos apresentou-se como uma técnica útil para demonstrar as alterações no ambiente estudado.

Estudos desta natureza constituem-se de ferramentas importantes para a tomada de decisão dos gestores municipais, na busca de um crescimento mais harmônico das cidades, compatibilizando as necessidades dos moradores por moradias e serviços públicos com os remanescentes naturais, que tem igual importância para a qualidade de vida da população. Assim estes resultados, quando analisados de preferência em conjunto com o maior número de estudos, realizados por equipes multidisciplinares tecnicamente habilitadas, podem ser uma "ferramenta" utilizada pelos gestores para avaliar e realizar as medidas administrativas necessárias para a garantia da função socioambiental da área.

\section{Agradecimentos}

F. Fisch agradece à CAPES/PROSUP pela bolsa de doutorado concedida, e J. O. Branco agradece ao Conselho Nacional de Desenvolvimento Científico e Tecnológico/CNPq pela bolsa de produtividade recebida durante a elaboração deste trabalho. 


\section{REFERÊNCIAS}

ALMEIDA, P.; DURIAVICH, M.; NAPOLITANO, R.; FEOLI, F. Aplicación de técnicas SIG, sensoramiento remoto y análisis multicriterio para la detección de impactos antropogénicos en la cobertura de suelos y su proyección para el 2010. Caso de estudio: Estuario de Santos (Brasil), Revista Tecnológica ESPOL - RTE, v. 22 (1): 73-79, 2009.

ALVES, C. D.; PEREIRA, M. N.; FLORENZANO, T. G. Mapeamento das novas formas de ocupação urbana por meio da análise orientada a objeto. Estudo de caso: Aglomeração Urbana de Piracicaba, In: XIV SIMPÓSIO BRASILEIRO DE SENSORIAMENTO REMOTO, 2009, Anais... Natal, Brasil, 25-30 abril 2009, INPE, p. 569-576.

ARAÚJO, M. V.; LIMA e COSTA, S. S.; PORTELA, J. P.; SILVA da CRUZ, P. Análise geoambiental da Área de Proteção Ambiental (APA) do Estuário do rio Ceará - Ceará Brasil. Geografia - 2008 - Universidade Estadual de Londrina, Departamento de Geociências, v. 17, n. 2, jul./dez., p. 25-36, 2008.

ARAÚJO, M. L.; RODRIGUES, J. E. C. R.; LUZ, L. M. Estudo da Cobertura Vegetal em Áreas de Expansão Urbana, Utilizando Sensores de Alta Resolução Espacial no Bairro do Tenoné-Belém/PA, In: XV SIMPÓSIO BRASILEIRO DE SENSORIAMENTO REMOTO SBSR,Curitiba, PR, Brasil,2011, Anais..., 30 de abril a 05 de maio de 2011, INPE p.67866793.

ARAÚJO, M. V.; FREIRE, G. S. S. Utilização de SIG nos estudos ambientais do estuário do rio Acaraú - Ceará, GEONOMOS, 15(2): 09 - 19, 2007.

ARAúJO, S. A.; SCOLARO, T. L.; REIS, F. H.; PETERMANN, R. M. Climatologia do ecossistema Saco da Fazenda, Itajaí, SC. In: Estuário do Rio Itajaí-Açu, Santa Catarina: caracterização ambiental e alterações antrópicas. ed. Univali, Itajaí, SC., 2009, p. 43-62.

BAPTISTA, A. C.; CALIJURI, M. L. 2007. Caracterização espaço-temporal por sensoriamento remoto da expansão urbana na APA Petrópolis, In: XIII SIMPÓSIO BRASILEIRO DE SENSORIAMENTO REMOTO, Florianópolis, Brasil, 2007, Anais... 21-26 abril de 2007, INPE, p. 5091-5098.

BARROS, A. O.; CASTANHA, M.; SCHWENK, L. M. Classificação de uso da terra no município de Lucas do Rio Verde: uma análise da confiabilidade na classificação automática e manual de imagem Landsat nas áreas de preservação permanente, In: XV SIMPÓSIO BRASILEIRO DE SENSORIAMENTO REMOTO - SBSR, Curitiba, PR, Brasil, 2011, Anais... 30 de abril a 05 de maio de 2011, INPE p.6089-6096.

BRANCO, J. O. Avifauna associada ao estuário do Saco da Fazenda, Itajaí, SC, Brasil. Revista Brasileira de Zoologia, v. 17(2): 384-394, 2000.

BUFFON, P.; FARINA, F. C.; SILVA da SILA, T.;

AYUP-ZOUAIN, R. N. Aplicação de técnicas de geoprocessamento na delimitação e avaliação da qualidade ambiental das Áreas de Preservação Permanente (APPs) no entorno do Campus do Vale da UFRGS, In: XV SIMPÓSIO BRASILEIRO DE SENSORIAMENTO REMOTO - SBSR, CURITIBA, PR, BRASIL, 2011, Anais... 30 de abril a 05 de maio de 2011, INPE p.4640-4646.

CARVALHO, A. P. F.; CARVALHO JÚNIOR, O. A.; GUIMARÃES, R. F.; ROCHA, V. M. S.; CÉSAR, C. S. Análise multitemporal de Imagens Ndvi em ações de reforma agrária. Espaço \& Geografia, v.5 (1): 139-152, 2002. 
CARVALHO JÚNIOR, O. A.; GUIRARÃES, R. F.; CARVALHO, A. P. F.; GOMES, R. A. T.; MELO, A. F.; SILVA, P. A. Processamento e análise de imagens multitemporais para 0 perímetro de irrigação de Gorutuba (MG). In: XII SIMPÓSIO BRASILEIRO DE SENSORIAMENTO REMOTO, Goiânia, Brasil, 2005, Anais... 16-21 abril 2005, INPE, p. 473-480.

CASTRO, L. A.; MELO, F. R.; ROSSETE, A. N. Avaliação da paisagem na gleba Cavalcante, Nova Xavantina, Mato Grosso, no período de 1990 - 2011, CAMPOTERRITÓRIO: Revista de Geografia Agrária, v. 8, n. 15, p. 1-24, fev.,2013.

FERREIRA, J. H. D.; OLIVEIRA, M. A.; FERREIRA, R. J. D.; VIERO, G. P.; PEREIRA, P. S.; SOUZA FILHO, E. E. S. O uso de imagens de satélite de média resolução na avaliação da expansão Urbana na bacia hidrográfica do Tibagi - PR, Revista Brasileira de Cartografia, n. 61/04: 375-383, 2009.

FERREIRA, L. S. FRANÇA, R. S.; VARELA da SILVA, A.; CLEMENTINO, M. L. M. O uso dos Sistemas de Informações Geográficas (SIG) para subsidiar políticas públicas na Região Metropolitana de Natal, GEOTemas, Pau dos Ferros, Rio Grande do Norte, Brasil, v. 1, n. 1, p. 15-20, 2011.

FISCH, F. Sucessão espaço-temporal da integridade da paisagem e da biota do saco fazenda (Itajaí, Santa Catarina, Brasil) e proposição de um índice integrado de qualidade ambiental. Programa de Pós-Graduação em Ciência e Tecnologia Ambiental. Centro De Ciências Tecnológicas da Terra e do Mar - CTTMar - UNIVALI. Itajai, 114 p. il., 2015.

FISCH, F.; MENEZES, J. T.; BRANCO, J. O. Análise da paisagem na região do saco da fazenda, Itajaí/SC através do sensoriamento remoto. Boletim de Geografia, Maringá, v. 34, n. 1, p. 96-107, 2016.

FLORES, P. M.; GUIMARÃES, R. F.; CARVALHO JÚNIOR, O. A.; GOMES, R. A. T. Análise multitemporal da expansão agrícola no município de Barreiras - Bahia (1988 - 2008), CAMPO-TERRITÓRIO: Revista de Geografia Agrária, v. 7, n. 14, p. 1-19, 2012.

HUZUI, A. E.; ABDELKADER, A.; PATRU-STUPARIU, I. Analysing urban dynamics using multitemporal satellite images in the case of a mountain area, Sinaia (Romania), International Journal of Digital Earth, p. 1-17, 2011.

ITAJAÍ, 2004. Lei Municipal no 4.063 de 02 de abril de 2004. Leis Municipais. Denomina baía localizada no bairro Fazenda, Disponível em:<http://portaldocidadao.itajai.sc.gov.br/servico link/28>. Acesso em 15 julho 2013.

ITAJAÍ, 2007. Decreto Municipal no 8.107 de 25 de janeiro de 2007. Leis Municipais. Dispõe sobre a criação e instalação do Parque Natural Municipal do Atalaia, Disponível em:<http://portaldocidadao.itajai.sc.gov.br/servico link/28>. Acesso em 20 agosto 2013.

ITAJAí, 2008. Decreto Municipal no 8.513 de 8 de março de 2008. Leis Municipais. Dispõe sobre a criação da Unidade de Conservação do Saco da Fazenda, Disponível em:<http://portaldocidadao.itajai.sc.gov.br/servico link/28>. Acessoem 15 julho 2013.

LANGLEY, S. K.; CHESHIRE, H. M.; HUMES, K. S. A comparison of single date and multitemporal satellite image classifications in a semi-arid grassland. Journal of Arid Environments, v. 49, n. 2, p. 401-411, 2001.

LI, G.; WENG, Q. Measuring the quality of life in city of Indianapolis by integration of remote sensing and census data, International Journal of Remote Sensing, 28(2): 249-267, 2007. 
MORATO, R.G.;KAWAKUBO, F. S.; HAYAKAWA, E. H.; PÉREZ MACHADO, R. P.Análise da expansão urbana por meio de composições coloridas multitemporais, Mercator, Fortaleza, v. 10, n. 22, p. 221-231, 2011.

OLIVEIRA, I. M.; COSTA, S. M. F. Monitoramento da expansao urbana, utilizando dados de Sensoriamento remoto - estudo de caso. In: X SIMPÓSIO BRASILEIRO DE SENSORIAMENTO REMORO-SBSR ,2001, Foz do Iguaçu, Anais... 21-26 abril 2001 INPE, Sessão Técnica Oral-Iniciação Científica, p. 1131-1138.

PASCOAL JUNIOR, P. S.; DAMASCENA, L. S.; LIMA, C. C. U. 2013. Avaliação multitemporal da dinâmica de uso e ocupação do solo nas imediações do estuário da RESEX Marinha Baía do Iguape: Realidade e Perspectivas para o gerenciamento. In: XVI SIMPÓSIO BRASILEIRO DE SENSORIAMENTO REMOTO - SBSR, 2013, Foz do Iguaçu, PR, Brasil, Anais... 13 a 18 de abril de 2013, INPE, p. 5428-5434.

PEDRON, F. A.; DALMOLIN, R. S. D.; AZEVEDO, A. C.; BOTELHO, M. R.; ROSA, A. S. Análise da dinâmica espacial da ocupação das terras e seus conflitos de uso no perímetro urbano de Santa Maria - RS (1975 - 2002), Ciência Rural, Santa Maria, v.36, n.6, p.17561764, 2006.

PETER, A.R.; SEVERO, A. C. M. ; MARTH, J. D. O uso e análise de técnicas de classificação de imagens de satélite para elaboração do mapa de cobertura vegetal e usos da terra - um estudo de caso da microbacia do arroio João Padre, Pelotas-RS, XIX CONGRESSO DE INICIAÇÃO CIENTÍFICA-CIC; XII ENCONTRO DE PÓS GRADUAÇÃOENPOS, II MOSTRA CIENTÍFICA-MC, UFP, 2010, Anais... 9-11 novembro.2010, p.1-4.

PINHEIRO JÚNIOR, J. R.; ALENCAS da COSTA, L.; VAZ dos SANTOS, M. C.; GOMES, L. $\mathrm{N}$. Análise temporal da paisagem do Parque Estadual do Bacanga utilizando Imagens dos Satélites SPOT-3 e CBERS-2, In: XIII SIMPÓSIO BRASILEIRO DE SENSORIAMENTO REMOTO, 2007, Florianópolis, Brasil, Anais... 21-26 abril 2007, INPE, p. 1023-1030.

ROCHA, B. A.; CLAUDINO-SALES, V. C.; SALES, M. C. L. Geoambientes, uso e ocupação do espaço no estuário do rio Apodi-Mossoró, Rio Grande do Norte, nordeste do Brasil. REDE - Revista Eletrônica do Prodema, Fortaleza, v. 7, n.2, p. 60-75, 2011.

SAMPAIO, C. S. Uso do solo no entorno do Parque Nacional de Brasília: Uma Análise Multitemporal. Revista Brasileira de Cartografia, n. 58/02, p. 155-162, 2006.

SANTOS, R. F (Org.). Vulnerabilidade Ambiental - Desastres Naturais ou Fenômenos Induzidos? Brasília: MMA, 2007. 192 p.

SCHETTINI, C. A. F. Hidrologia do Saco da Fazenda, ITAJAÍ, SC. Brazilian Journal of Aquatic Science and Technology-BJAST, 12 (1): 49-58, 2008.

SILVA S. J.; OLIVEIRA, T. H.; TORRES, M. F. A. 2009. Utilização de imagens aéreas na análise temporal de ambientes impactados: Estudo de caso - Estuário do rio Jaboatão Pernambuco - Brasil, In: XIV SIMPÓSIO BRASILEIRO DE SENSORIAMENTO REMOTO, 2009, Natal, Brasil. Anais... 25-30 abril 2009, INPE, p. 6257-6263.

SILVA, V. C. L.; SILVA, R. M. Análise da cobertura vegetal em Lucena entre 1970/2005 usando ecologia da paisagem, SIG e Sensoriamento Remoto. Caminhos de Geografia, Uberlândia, v. 12, n. 37 , p. 8 - 20, 2011.

TOGNELLA-DE-ROSA, M. M. P.; OLIVEIRA, R. G.; LUGLI, D. O.; WILLRICH, J. F.; MEIRELES, R. P.; POLETTO, T. V. Replantio da vegetação do ecossistema manguezal do Saco da Fazenda, Itajaí (SC), Notas Técnicas-Facimar, v.6, p. 85-91, 2002. 
UMBELINO, G. J. M.; MACEDO, D. R. Uso de Sistemas Informativos Geográficos (SIG's) na avaliação da dinâmica evolutiva de áreas urbanas: um estudo a partir dos Pólos Mineiros. In: XV ENCONTRO NACIONAL DE ESTUDOS POPULACIONAIS, ABEP, 2006, Caxambú-MG - Brasil Anais...18 - 22 de set., 2006, p. 1-15.

\section{VARGAS, B. M. Relatório da Comissão de Estudos do Porto de Itajahy e Rio}

Cachoeira.1935, p.135.

VIEIRA, C. H. S. D.; BIONDI, D. Análise da dinâmica da cobertura Vegetal de Curitiba, PR (de 1986 a 2004), utilizando imagens LandsatTm, Revista Árvore, Viçosa-MG, v.32 (3): 479-487, 2008.

VILA NOVA, F. V. P.; TORRES, M. F. A. Avaliação ambiental em Unidades de Conservação: Estuário do Rio Maracaípe, Ipojuca-Pe, Brasil, Revista de Geografia (UFPE), v. 29 (3): 199224, 2012.

XAVIER, S. C.; BASTOS, C. A. B. Estudo do crescimento urbano aplicado ao mapeamento geotécnico: uma metodologia de análise, Revista Brasileira de Cartografia, n. 62/04, p.. 583-593, 2010.

\section{NOTAS DE AUTOR}

\section{CONTRIBUIÇÃO DE AUTORIA}

Fabiane Fisch - Concepção do manuscrito. Coleta de dados. Análise de dados. Participação ativa da discussão dos resultados. Elaboração do manuscrito, revisão e aprovação da versão final do trabalho.

Joaquim Olinto Branco - Concepção do manuscrito. Participação ativa da discussão dos resultados. Revisão e aprovação da versão final do trabalho.

Dagoberto Port - Concepção do manuscrito. Coleta de dados. Análise de dados. Participação ativa da discussão dos resultados. Elaboração do manuscrito, revisão e aprovação da versão final do trabalho.

João Thadeu de Menezes - Concepção do manuscrito. Análise de dados. Revisão e aprovação da versão final do trabalho.

\section{FINANCIAMENTO}

Não se aplica.

\section{CONSENTIMENTO DE USO DE IMAGEM}

Não se aplica.

\section{APROVAÇÃO DE COMITÊ DE ÉTICA EM PESQUISA}

Não se aplica.

\section{CONFLITO DE INTERESSES}

Não se aplica.

\section{LICENÇA DE USO}

Este artigo está licenciado sob a Licença Creative Commons CC-BY. Com essa licença você pode compartilhar, adaptar, criar para qualquer fim, desde que atribua a autoria da obra.

\section{HISTÓRICO}

Recebido em: 05-09-2016

Aprovado em: 10-09-2018 